\title{
Therapeutic targeting of oncogenic transforming growth factor- $\beta 1$ signaling by antisense oligonucleotides in oral squamous cell carcinoma
}

\author{
SEONG-GON KIM and JI-YOUNG SONG ${ }^{1}$ \\ Department of Oral and Maxillofacial Surgery, College of Dentistry, Gangneung-Wonju National University, \\ Gangneung 210-702, Republic of Korea
}

Received February 2, 2012; Accepted April 23, 2012

DOI: $10.3892 /$ or.2012.1811

\begin{abstract}
The transforming growth factor- $\beta 1$ (TGF- $\beta 1$ ) signaling pathway is important in human oral squamous cell carcinoma (OSCC). Accordingly, the aims of this study were to evaluate the effect of antisense TGF- $\beta 1$ oligonucleotides (ODNs) on OSCC in cell culture and in a xenograft model, as well as to evaluate any effects ODNs have on proliferating cell nuclear antigen (PCNA) and matrix metalloproteinase-2 (MMP-2) expression in the xenograft model. We performed real-time cell electronic sensing (RT-CES) to determine the effect of antisense TGF- $\beta 1$ ODNs on SCC- 9 cell growth. To examine the in vivo effect of antisense TGF- $\beta 1$ ODN therapy, SCC -9 cells were grafted into nude mice. Antisense ODNs were injected into the mass daily. Tumor size, body weight and duration of survival were assessed daily. Specimens from the main mass were used for immunohistochemical staining to analyze PCNA and MMP-2 expression. In vitro treatment with antisense TGF- $\beta 1$ ODNs decreased TGF- $\beta 1$ expression and growth of SCC-9 cells. In the xenograft model, the antisense TGF- $\beta 1$ ODN group exhibited a significantly decreased tumor growth rate compared to the control, which received Dulbecco's modified Eagle's medium (DMEM) $(\mathrm{P}=0.022)$. However, mean survival time and body weights were not significantly different between the groups $(\mathrm{P}>0.05)$. Immunohistochemistry showed that tumors from animals that received antisense TGF- $\beta 1$ ODNs had significantly lower expression levels of PCNA and MMP-2 compared to tumors from animals in the DMEM group $(\mathrm{P}<0.05)$. In conclusion, antisense TGF- $\beta 1$ ODN therapy significantly inhibits tumor growth compared to controls, however, there are no signifi-
\end{abstract}

Correspondence to: Dr Seong-Gon Kim, Department of Oral and Maxillofacial Surgery, College of Dentistry, Gangneung-Wonju National University, Gangneung 210-702, Republic of Korea E-mail: epker@chol.com

Present address: ${ }^{1}$ Department of Oral and Maxillofacial Surgery, Jeju National University Hospital, Jeju 690-767, Republic of Korea

Key words: transforming growth factor- $\beta 1$, squamous cell carcinoma, matrix metalloproteinase-2, antisense cant differences between groups with respect to changes in body weight.

\section{Introduction}

Oral squamous cell carcinoma (OSCC) is the most common malignant tumor of epithelial origin in the head and neck area, and it commonly metastasizes (1). Many studies have examined the mechanism of metastasis (2). However, the exact pathways involved are still unclear. The transforming growth factor- $\beta 1$ (TGF- $\beta 1$ ) (3) and matrix metalloproteinase (MMP) families $(4,5)$ are involved in metastasis of gastrointestinal (GI) tract tumors. TGF- $\beta 1$ is expressed in normal epithelium of the GI tract. In this setting, it is known to inhibit proliferation through the caspase pathway (6).

During tumor progression, however, TGF- $\beta 1$ can stimulate cancer cell growth through a different mechanism and is involved in metastasis (6). In particular, TGF- $\beta 1$ is involved in epithelial to mesenchymal transition (EMT) (7). When cells of epithelial origin acquire mesenchymal features, they start to migrate into the connective tissue by breaking down the basement membrane. In addition, TGF- $\beta 1$ is highly expressed in areas of inflammation and it activates the growth of fibroblasts (8). In a similar manner, TGF- $\beta 1$ may increase the growth of cancer cells that have undergone EMT.

The MMP family of enzymes is involved in tissue remodeling under both physiologic and pathologic conditions (9). MMPs are zinc-dependent endopeptidases that can degrade extracellular matrix (ECM) components (10). For example, decreased expression of MMPs is related to impaired tooth eruption (11). Overexpression of several MMPs has been linked to increased invasive and metastatic potential in a variety of cancers including OSCC $(2,4,5)$. MMP-2 has been implicated in TGF- $\beta 1$-induced invasion by pancreatic cancer cells (4).

MMP-2 is highly expressed in OSCC with lymph node metastasis, and OSCC cells in the metastatic lymph node highly express TGF- $\beta 1$ (12). Therefore, TGF- $\beta 1$ may be an attractive drug target for invasive OSCC. However, TGF- $\beta 1$ regulates biological process of normal cells. To administer a TGF- $\beta 1$ inhibitor systemically, an appropriate drug carrier is essential to avoid unwanted effects of the agent on normal cells. If the agent can be administered locally, systemic toxicity may 
be reduced. Antisense oligonucleotides (ODNs) are a relatively temporary way of inhibiting a target gene compared to small inhibitory RNAs (siRNA). If a proper delivery system can be identified for ODN, intracellular transportation also can be achieved efficiently. Considering that downregulation of a key gene is sometimes sufficient to cause apoptosis in cancer cells, repeated local administration of antisense ODN may be therapeutically useful for challenging OSCC.

The objective of this study was to evaluate the therapeutic effect of antisense TGF- $\beta 1$ ODN in SCC-9. First, we assessed whether the ODN caused reduced protein expression by reverse transcriptase-polymerase chain reaction (RT-PCR) and western blot analysis. Second, cellular growth inhibition was examined by real time-cell electronic sensing (RT-CES) analysis. Third, the antitumor effect of antisense TGF- $\beta 1$ ODN therapy was evaluated in a tumor xenograft model. Finally, tumor cell expression of proliferating cellular nuclear antigen (PCNA) and MMP-2 in the xenograft model was evaluated by immunohistochemistry.

\section{Materials and methods}

Cell culture and RT-CES. SCC-9 cells (human tongue squamous cell carcinoma) (American Type Culture Collection; Manassas, VA, USA) were maintained as monolayer cultures in Dulbecco's modified Eagle's medium (DMEM) (Invitrogen, Carlsbad, CA, USA) supplemented with $10 \%$ fetal bovine serum containing L-glutamine, vitamins (Life Technologies, Inc., Grand Island, NY, USA) and penicillin-streptomycin (Flow Laboratories, Inc., Rockville, MD, USA). The cells were incubated in a mixture of $5 \% \mathrm{CO}_{2}$ and $95 \%$ air at $37^{\circ} \mathrm{C}$. The cultures were maintained for no longer than 12 weeks after recovery from frozen stocks.

Label-free detection of cellular growth was conducted by RT-CES based on impedance measurements using the xCELLigence ${ }^{\circledR}$ system (Roche Applied Science, Penzberg, Germany) and special 96-well gold-plated culture dishes in which SCC- 9 cells were grown. The antisense TGF- $\beta 1$ ODN was designed as 5'-CTGTTGTACAGGGCGAGC-3'. The sense TGF- $\beta 1$ ODN was 5'-GCTCGCCCTGTACAACAG-3'. SCC-9 cells were transfected at $80 \%$ confluence with sense or antisense TGF- $\beta 1$ ODNs using Lipofectamine 2000 (Invitrogen) according to the manufacturer's instructions. Briefly, we added $20 \mu \mathrm{l}$ of the ODN mixture at a concentration $10 \mathrm{pM}$ to each well $42 \mathrm{~h}$ after the initial culture under serum-free conditions. In the control wells, cells were grown in the same medium without ODNs. The cell index values, derived from the measured impedance, were determined every hour for 4 days.

Extraction of total-RNA, cDNA synthesis and RT-PCR. The culture medium was removed and total-RNA was extracted using Tri-Reagent (Molecular Research Center, Inc., Cincinnati, $\mathrm{OH}$, USA) according to the manufacturer's protocol. The concentration of total-RNA was measured using a spectrophotometer (Ultrospec 2000 UV/visible spectrophotometer; Amersham, Pharmacia Biotech, Piscataway, NJ, USA).

The cDNA was synthesized from total-RNA using a reverse transcriptase kit (Invitrogen). The reactions were primed with $3 \mu \mathrm{l}$ of oligo(dt) and $1 \mu \mathrm{l}$ of $10 \mathrm{mM}$ dNTP mixture. DEPCtreated tertiary distilled water was added to reach a total volume of $40 \mu \mathrm{l}$. The reaction was performed at $65^{\circ} \mathrm{C}$ for $5 \mathrm{~min}$ and the temperature was slowly decreased to room temperature (RT). Then, $2 \mu \mathrm{l}$ of $10 \mathrm{X}$ first-strand buffer, $4 \mu \mathrm{l}$ of $25 \mathrm{mM} \mathrm{MgCl}_{2}, 2 \mu \mathrm{l}$ of $0.1 \mathrm{M}$ DTT, $1 \mu \mathrm{l}$ of RNased Block ribonucleotide inhibitor (40 U/ $/ \mu \mathrm{l}$ ) and $1 \mu \mathrm{l}$ RTase were added. The total volume was $50 \mu \mathrm{l}$, and the reaction was performed at $42^{\circ} \mathrm{C}$ for $1 \mathrm{~h}$.

PCR was performed with $2.5 \mu \mathrm{l}$ of cDNA. 20 -mer primers were selected from the human TGF- $\beta 1$ coding region sequence (forward, GCCAGAGTGGTTATCTTTTG; backward, GCTG AAGCAATAGTTGGTGT). The primer sequences for glyceraldehyde 3-phosphate dehydrogenase (GAPDH) were: forward, AGGACTCATGACCACAGTCCA and backward, TGTTGCTGTAGCCAAATTCGTT. The reaction mixture consisted of primers, $10 \mathrm{X}$ reaction buffer, $25 \mathrm{mM} \mathrm{MgCl}$, $1 \mathrm{mM}$ dNTP and TaqDNA polymerase (Promega, Madison, WI, USA). The total volume was $50 \mu \mathrm{l}$. The PCR conditions were: after denaturing at $95^{\circ} \mathrm{C}$ for $10 \mathrm{~min}$, the temperature was cycled at $95^{\circ} \mathrm{C}$ for $30 \mathrm{sec}, 58^{\circ} \mathrm{C}$ for $30 \mathrm{sec}, 60^{\circ} \mathrm{C}$ for $30 \mathrm{sec}$. Each specimen underwent 33 cycles. The PCR products were run on a $1.5 \%$ agarose gel and stained with ethidium bromide solution.

Western blot analysis. Whole cells were lysed in ProteoJET ${ }^{\mathrm{TM}}$ Mammalian Cell Lysis Reagent (Thermo Scientific) containing protease inhibitor cocktail (Sigma-Aldrich). Proteins were separated on $10 \%$ SDS-polyacrylamide gels and transferred to PVDF membranes. Blots were blocked with 5\% skim milk powder in Tris-buffered DMEM (20 mM Tris-HCl, 137 mM NaCl, pH 7.6) containing $0.1 \%$ Tween-20 (TBS-T buffer) for $1 \mathrm{~h}$ at RT. Western blot analyses were performed with TGF- $\beta 1$ (sc-146) (Santa Cruz Biotechnology, Inc., Santa Cruz, CA, USA) and anti- $\beta$-actin (Sigma-Aldrich) antibodies. Primary antibodies were added to the TBS-T buffer at a 1:1,000 dilution and incubated for $90 \mathrm{~min}$ at RT prior to incubation with HRP-conjugated secondary antibodies (1:5,000 dilution; Santa Cruz Biotechnology, Inc.) for $1 \mathrm{~h}$ at room temperature. Proteins were detected using ChemiDoc ${ }^{\mathrm{TM}}$ XRS+ (Bio-Rad, Hercules, CA, USA).

Xenograft study. Seven-week-old male athymic nude mice were purchased from Orient Bioco (Seoul, Korea). The mice were used in accordance with the Animal Care and Use Guidelines of the College of Dentistry at Gangneung-Wonju National University (GWNU 2011-26). SCC-9 cells were harvested from subconfluent cultures and a viable cell suspension was used for injections. To induce anesthesia, the mice were injected intramuscularly with $1.5 \mathrm{mg} / \mathrm{kg}$ of zolazepam (Zoletil ${ }^{\circledR}$; Virbac Laboratories, Carros, France) and $3.5 \mathrm{mg} /$ $\mathrm{kg}$ of xylazine hydrochloride (Rumpun ${ }^{\circledR}$; Bayer Korea, Seoul, Korea). The injection solution consisted of $5 \times 10^{5}$ cells resuspended in $50 \mu \mathrm{l}$ of $\mathrm{Ca}^{2+}$ - and $\mathrm{Mg}^{2+}$-free Hanks' balanced salt solution (HBSS), and this was injected into the submandibular gland in the flank using a 27-gauge hypodermic needle with a 1-ml syringe as described previously (13). After the injections, mice were randomly assigned to 1 of 3 groups (sense TGF- $\beta 1$ ODN, antisense TGF- $\beta 1$ ODN and DMEM). Treatment was started after a tumor mass was definitively identified. Tumor size was calculated using the following formula: mass volume $=\mathrm{a}($ long distance $) \mathrm{x} \mathrm{b}$ (short distance $)^{2} / 2$ (14).

Sense and antisense TGF- $\beta 1$ ODNs were synthesized by Bioneer (Chungwon, Korea). The drug was administered daily 
A

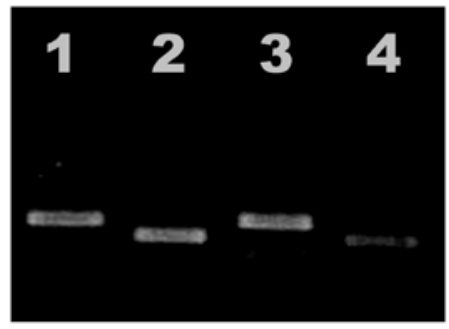

B

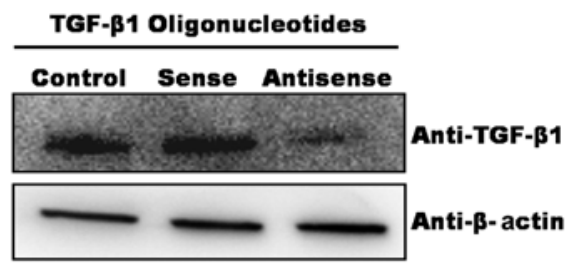

Figure 1. (A) RT-PCR showed that antisense TGF- $\beta 1$ ODN decreased the level of TGF- $\beta 1$ mRNA (lane 4) compared to DMEM (lane 2). The level of GAPDH mRNA was similar between groups (lane 1-DMEM treatment and lane 3-antisense treatment). (B) Western blot analysis for whole cell lysates showed that TGF- $\beta 1$ significantly decreased with antisense ODN treatment compared to DMEM or sense ODN treatment.

into the main mass. The dosages were: i) $100 \mu$ l of DMEM, ii) $100 \mu \mathrm{l}$ of $100 \mathrm{pM}$ sense TGF- $\beta 1 \mathrm{ODN}$ or iii) $100 \mu \mathrm{l}$ of $100 \mathrm{pM}$ antisense TGF- $\beta 1$ ODN. The vehicle for the sense and antisense ODN was Lipofectamine 2000 (Invitrogen). Changes in mass size and body weight were observed daily. To compare mass size and body weight, the initial values at the start of treatment were set to 1 . The relative mass size and body weight at each observation point were calculated. The differences in mass size and body weight between groups were compared by independent sample t-tests. The death of a mouse was recorded and the data were used for the survival analysis. Survival was compared by the Kaplan-Meier method and the difference between the groups was evaluated by the log rank test. The significance level was set at $\mathrm{P}<0.05$.

Immunohistochemical staining. The following primary antibodies for immunohistochemical analysis were purchased: mouse monoclonal antibody to PCNA (sc-25280) (Santa Cruz Biotechnology, Inc.) and mouse monoclonal antibody to MMP-2 (sc-13595) (Santa Cruz Biotechnology, Inc.). The dilution rates were 1:50 for PCNA and 1:20 for MMP-2. The largest tumor from each mouse was used for immunohistochemical staining and 4- $\mu$ m-thick sections were cut. Universal LSAB+ kits (Dako, Glostrup, Denmark) were used for immunohistochemistry and the subsequent procedures were performed according to the manufacturer's protocols. Immunostaining without primary antibodies served as a negative control. The sections were counterstained with Mayer hematoxylin. Two pathologists blinded to the original group classification reviewed all of the slides. The slides were evaluated for intensity and area of staining. The intensity scales were (-) for invisible or trace staining in a focal area, $(+)$ for visible staining in a moderate area, and $(++)$ for dense, strong staining in an extensive area. Three different sections

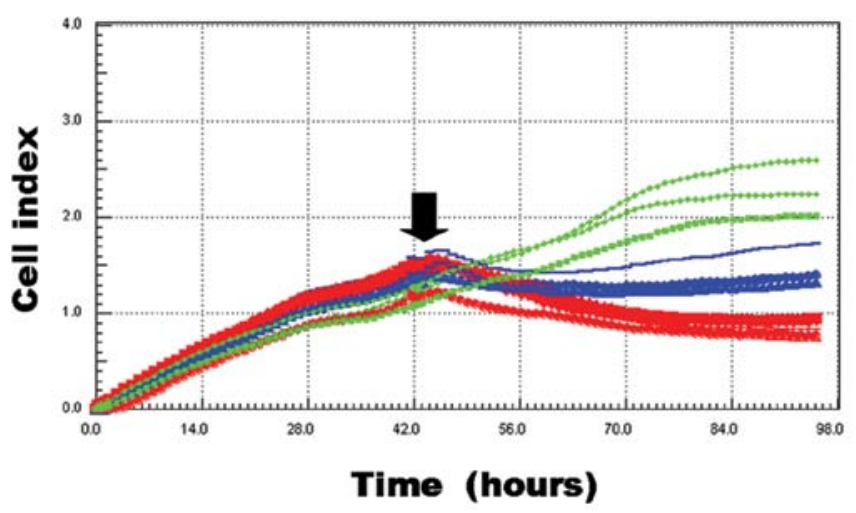

Figure 2. RT-CES-monitored cell growth (green, DMEM; blue, sense ODN; red, antisense ODN). The sharp drop at $\sim 42 \mathrm{~h}$ (arrow) was due to application of the antisense ODN to the cultured cells.

per specimen were used for the analysis. The average value of a sample was considered to be the immunohistochemical activity of the sample. The difference between the groups was analyzed by the independent samples t-test and significance was set at $\mathrm{P}<0.05$.

\section{Results}

Antisense TGF- $\beta 1$ ODN decreases the levels of TGF- $\beta 1$ and cellular growth. As shown in Fig. 1A, RT-PCR showed that antisense TGF- $\beta 1$ ODN decreased the level of TGF- $\beta 1$ mRNA. Western blot analysis experiments showed that antisense TGF- $\beta 1$ ODN decreased the level of TGF- $\beta 1$ protein (Fig. 1B). In addition, cellular growth was significantly inhibited after antisense TGF- $\beta 1$ ODN treatment (Fig. 2). Forty-eight hours after drug administration, the cell index of the antisense TGF- $\beta 1$ ODN group was $0.87 \pm 0.08$. That of the DMEM and sense TGF- $\beta 1$ ODN groups were $2.28 \pm 0.35$ and $1.38 \pm 0.16$, respectively. When we compared the cell index of the antisense TGF- $\beta 1$ ODN group to that of the DMEM group, the difference was statistically significant $(\mathrm{P}=0.003)$. The difference between the sense TGF- $\beta 1$ ODN group and the antisense TGF- $\beta 1$ ODN group was also statistically significant $(\mathrm{P}<0.001)$.

Antisense TGF- $\beta 1$ ODN reduces mass size. When we compared relative tumor size 21 days after the initial treatment, the DMEM group, sense ODN group and antisense ODN group had relative tumor mass sizes of $6.30 \pm 0.72,5.26 \pm 1.15$, and 3.37 \pm 1.76 , respectively (Fig. 3A). There was a significant difference between the DMEM group and antisense ODN group $(\mathrm{P}=0.022)$. However, there were no significant differences between the other groups $(\mathrm{P}>0.05)$. When we compared relative body weight 21 days after the initial treatment, the DMEM group, sense ODN group and antisense ODN group had relative body weights of $0.99 \pm 0.13,1.02 \pm 0.01$ and $0.93 \pm 0.19$, respectively (Fig. 3B). There were no significant differences between groups $(\mathrm{P}>0.05)$. With respect to survival, the mean survival time of the DMEM group was 17.0 \pm 3.0 days (Fig. 3C). The mean survival time of the sense ODN and antisense ODN groups were $18.0 \pm 3.0$ days and 18.0 \pm 3.0 days, respectively. When survival time was compared between groups, there were no significant differences $(\mathrm{P}>0.05)$. 
Table I. Immunoreactivity of PCNA and MMP-2.

\begin{tabular}{|c|c|c|c|c|c|c|c|c|c|}
\hline & \multicolumn{3}{|c|}{ DMEM group } & \multicolumn{3}{|c|}{ TGF- $\beta 1$ sense group } & \multicolumn{3}{|c|}{ TGF- $\beta 1$ antisense group } \\
\hline & 0 & + & ++ & 0 & + & ++ & 0 & + & ++ \\
\hline PCNA & 0 & 0 & 5 & 0 & 2 & 3 & 3 & 2 & 0 \\
\hline MMP-2 & 0 & 1 & 4 & 1 & 2 & 2 & 2 & 2 & 1 \\
\hline
\end{tabular}

DMEM, Dulbecco's modified Eagle's medium; TGF- $\beta 1$, transforming growth factor- $\beta 1$; PCNA, proliferating cellular nuclear antigen; MMP-2, matrix metalloproteinase-2.

A

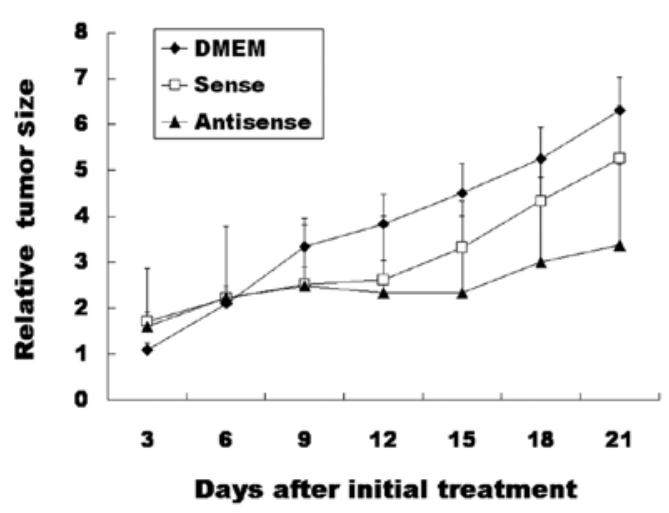

B
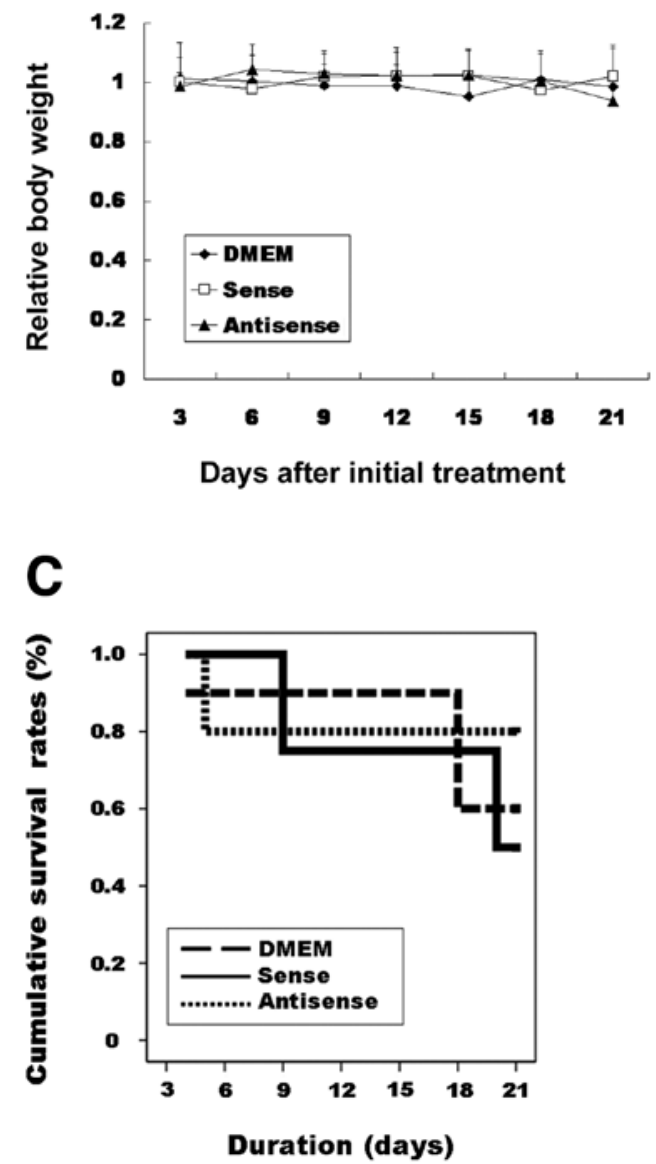

Figure 3. Tumor xenograft in nude mice. (A) Relative tumor size. (B) Relative body weight. (C) Cumulative survival curve.
Antisense TGF- $\beta 1$ ODN therapy decreases PCNA and MMP-2 expression in a tumor of the xenograft model. The PCNA and MMP-2 expression patterns are presented in Table I. The DMEM group and sense ODN group had relatively high expression levels of PCNA (Fig. 4A and B). In the DMEM group, sections from all mice showed strong expression of PCNA (5/5 mice). Two sections from animals in the sense ODN group showed visible PCNA staining, and sections from the 3 other mice showed strong staining. In contrast, in the antisense ODN group, the expression of PCNA was negligible in $3 / 5$ mice (- degree of staining) and visible in $2 / 5$ mice (+ degree of staining) (Fig. 4C). When the expression of PCNA in the antisense ODN group was compared to that of the DMEM group, the difference was statistically significant $(\mathrm{P}=0.003)$. However, there were no statistically significant differences between the other groups $(\mathrm{P}>0.05)$.

The DMEM group showed strong expression of MMP-2 in the sections from 4 mice $(80.0 \%)$ (Fig. 5A). The sense ODN group showed slightly reduced expression of MMP-2 compared to the DMEM group (Fig. 5B). However, in the antisense ODN group, the expression of MMP-2 was negligible in $2 / 5$ mice (- degree of staining) and visible in $2 / 5$ mice (+ degree of staining) (Fig. 5C). When the expression of MMP-2 in the antisense ODN group was compared with that in the DMEM group, the differences were statistically significant $(\mathrm{P}=0.046)$. However, there were no statistically significant differences between the other groups $(\mathrm{P}>0.05)$.

\section{Discussion}

TGF- $\beta 1$ is a potent inhibitor of growth for many cell types (15), including normal human oral keratinocytes (16). However, TGF- $\beta 1$ expression in neoplasia increases tumorigenicity, invasion and drug resistance (17). In this study, TGF- $\beta 1$ knockdown by antisense ODN in SCC-9 inhibited tumor cell growth both in vitro and in vivo. In addition, antisense TGF- $\beta 1$ ODN decreased the levels of PCNA and MMP-2 in a tumor xenograft model.

Many drugs have been designed to modify the TGF- $\beta 1$ signaling pathway (18). However, systemic administration of a TGF- $\beta 1$ blocker will have undesired effects on normal cells (19). Thus, targeting of TGF- $\beta 1$ should be specific for cancer cells. Local drug delivery has been tried in many tumor models. Additionally, antisense ODN is an effective tool for the suppression of a specific gene (20). However, slow uptakes into cells and rapid degradation in the cytoplasm have been obstacles to the systemic use of ODN for the treatment 

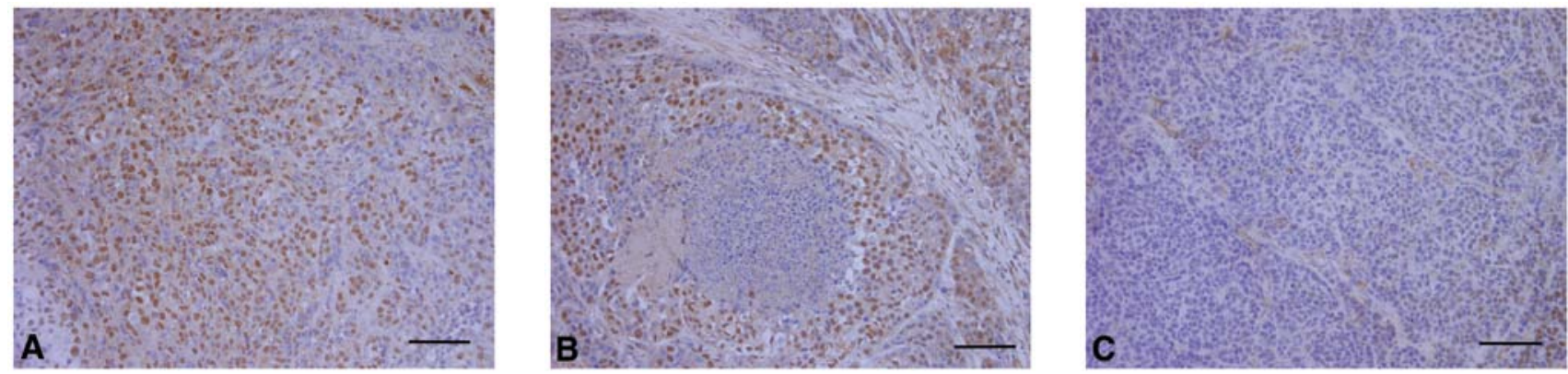

Figure 4. Immunohistochemical staining for PCNA. (A) DMEM group (bar, $100 \mu \mathrm{m}$ ). (B) TGF- $\beta 1$ sense group (bar, $100 \mu \mathrm{m}$ ). (C) TGF- $\beta 1$ antisense group (bar, $100 \mu \mathrm{m}$ ).
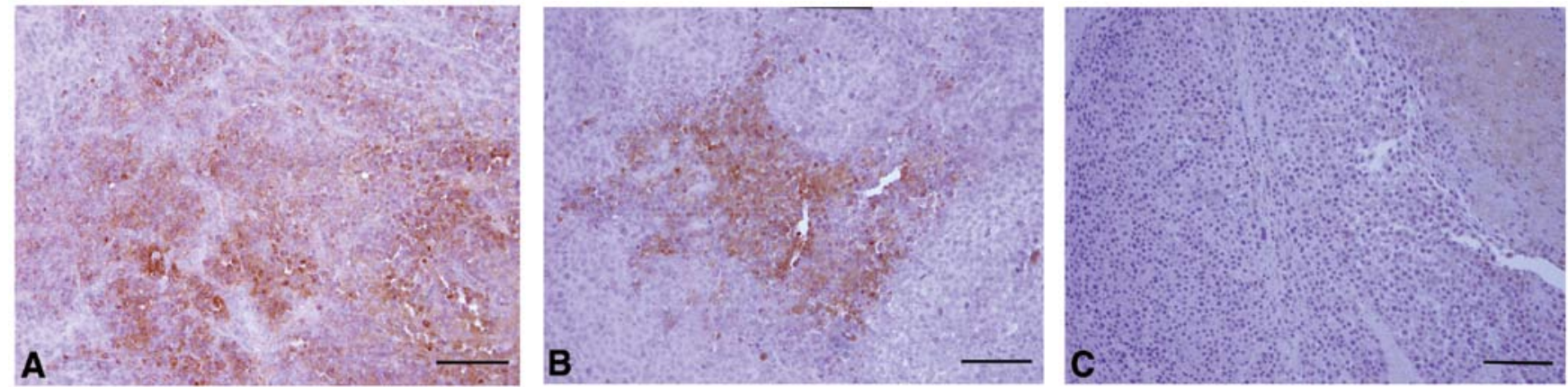

Figure 5. Immunohistochemical staining for MMP-2. (A) DMEM group (bar, $100 \mu \mathrm{m}$ ). (B) TGF- $\beta 1$ sense group (bar, $100 \mu \mathrm{m}$ ). (C) TGF- $\beta 1$ antisense group (bar, $100 \mu \mathrm{m}$ ).

of disease (21). If antisense ODN is delivered locally to the tumor, unwanted suppression of TGF- $\beta 1$ in normal cells may be avoided. In addition, use of the proper vehicle will increase transfection rates. In this study, antisense ODN packed in liposomes caused suppression of both target gene expression and SCC-9 growth (Figs. 1 and 2). Local administration of antisense TGF- $\beta 1$ ODN did not cause weight loss of experimental animals compared to control animals treated with DMEM (Fig. 3B). Antisense TGF- $\beta 1$ ODN also showed therapeutic effects in a xenograft model (Fig. 3A).

When siRNA is used, gene silencing is very specific to the target sequence (22). Like designing the siRNA, selection of the proper target sequence is a vital component of developing the therapeutic applications of ODN. We confirmed the gene silencing effect of the antisense ODN using RT-PCR and western blot analysis (Fig. 1). The antisense ODN caused significantly lower tumor cell growth compared to the corresponding sense ODN and DMEM treatments (Fig. 2). As siRNA and antisense ODN capitalize on similar methods of gene silencing $(20,21)$, the presented antisense ODN design may also be applicable to siRNA.

Expression levels of PCNA and MMP-2 were decreased by antisense TGF- $\beta 1$ ODN therapy (Figs. 4 and 5). MMPs are highly expressed in cancer cells showing EMT, and EMT may facilitate cancer progression toward a more invasive phenotype (23). TGF- $\beta 1$ expression is higher in metastatic tumors compared to primary tumors in a tumor-bearing murine model (24). In human OSCC, increased MMP levels correlate with increases in the TGF- $\beta 1$ signaling pathway (25). TGF- $\beta 1$ can increase the expression of MMP-2 in cancer cells $(4,26)$.
TGF- $\beta 1$ frequently co-localizes with MMP-2 in OSCC, and MMP-2 is highly expressed in OSCC with lymph node metastasis (12). Therefore, decreases in MMP-2 expression observed after antisense TGF- $\beta 1$ ODN treatment in the xenograft model might be due to lower levels of TGF- $\beta 1$ caused by the antisense TGF- $\beta 1$ ODN. Though metastasis was not evaluated in this study, tumors from animals treated with antisense TGF- $\beta 1$ ODN showed significantly less MMP-2 expression compared to those treated with DMEM (Fig. 5).

In conclusion, local delivery of antisense TGF- $\beta 1$ ODN resulted in significantly slower tumor growth and no significant differences in weight loss compared to animals that were similarly administered DMEM. However, antisense TGF- $\beta 1$ ODN did not prolong survival compared to DMEM. To confirm the effect of this treatment on survival, long-term observation is required. In addition, synergistic effects of combining antisense TGF- $\beta 1$ ODN with conventional chemotherapeutic agents warrants further investigation.

\section{Acknowledgements}

This study was supported by a grant from the NextGeneration BioGreen21 Program (Center for Nutraceutical \& Pharmaceutical Materials no. PJ009013), Rural Development Administration, Republic of Korea.

\section{References}

1. Kim ES, Kies M and Herbst RS: Novel therapeutics for head and neck cancer. Curr Opin Oncol 14: 334-342, 2002. 
2. Hong SD, Hong SP, Lee JI and Lim CY: Expression of matrix metalloproteinase-2 and -9 in oral squamous cell carcinomas with regard to the metastatic potential. Oral Oncol 36: 207-213, 2000.

3. Lionetti P, Pazzaglia A, Moriondo M, et al: Differing patterns of transforming growth factor- $\beta$ expression in normal intestinal mucosa and in active celiac disease. J Pediatr Gastroenterol Nutr 29: 308-313, 1999.

4. Ellenrieder V, Hendler SF, Ruhland C, Boeck W, Adler G and Gress TM: TGF- $\beta$-induced invasiveness of pancreatic cancer cells is mediated by matrix metalloproteinase- 2 and the urokinase plasminogen activator system. Int J Cancer 93: 204-211, 2001.

5. Sier CFM, Kubben FJGM, Ganesh S, et al: Tissue level of matrix metalloproteinases MMP-2 and MMP-9 are related to the overall survival of patients with gastric carcinoma. Br J Cancer 74 413-417, 1996.

6. Wakefield LM and Roberts AB: TGF- $\beta$ signaling: positive and negative effects on tumorigenesis. Curr Opin Genet Dev 12: 22-29, 2002

7. Thiery JP: Epithelial-mesenchymal transitions in tumour progression. Nat Rev Cancer 2: 442-454, 2002.

8. Kovasc EJ: Fibrogenic cytokines: The role of immune mediators in the development of scar tissue. Immunol Today 12: 17-23, 1991

9. Stetler-Stevenson WG, Aznavoorian S and Liotta LA: Tumor cel interactions with the extracellular matrix during invasion and metastasis. Annu Rev Cell Biol 9: 541-573, 1993.

10. Nagase H and Woessner JF Jr: Matrix metalloproteinases. J Biol Chem 274: 21491-21494, 1999.

11. Kim SG, Kim MH, Chae CH, Jung YK and Choi JY: Downregulation of matrix metalloproteinases in hyperplastic dental follicles results in abnormal tooth eruption. BMB Rep 41 : 322-327, 2008

12. Kim JY, Rotaru H and Kim SG: The clinical significance of the expression of TGF- $\beta 1$ and MMP-2 related to the regional lymph node metastasis in the oral squamous cell carcinoma. J Korean Oral Maxillofac Surg 33: 199-203, 2007.

13. Park YW, Kim SG, Choi JY and Lee SK: Recapitulating orthotopic tumor model through establishment of a parotid gland tumor with lung metastasis using HeLa cell injection into nude mice. Oncol Rep 23: 701-708, 2010.

14. Carlsson G, Gullberg B and Hafström L: Estimation of liver tumor volume using different formulas - an experimental study in rats. J Cancer Res Clin Oncol 105: 20-23, 1983.
15. Roberts $\mathrm{AB}$ and Sporn MB: The transforming growth factors In: Peptide Growth Factors and their Receptors I. Sporn MB and Roberts AB (eds). Springer, Berlin, pp419-472, 1990.

16. Prime SS, Matthews JB, Patel V, et al: TGF- $\beta$ receptor regulation mediates the response to exogenous ligand but is independent of the degree of cellular differentiation in human oral keratinocytes. Int J Cancer 56: 406-412, 1994.

17. Aiping H: Drug resistance and gene amplification potential regulated by transforming growth factor $\beta 1$ gene expression. Cancer Res 55: 1758-1762, 1995.

18. Yingling JM, Blanchard KL and Sawyer JS: Development of TGF- $\beta$ signaling inhibitors for cancer therapy. Nat Rev Drug Discov 3: 1011-1022, 2004

19. Moore LD, Isayeva T, Siegal GP and Ponnazhagan S: Clin Cancer Res 14: 4961-4970, 2008.

20. Woolf TM, Melton DA and Jennings CGB: Specificity of an antisense oligonucleotides in vivo. Proc Natl Acad Sci USA 89: 7305-7309, 1992

21. Thierry AR, Rahman A and Dritschilo A: Liposomal delivery as a new approach to transport antisense oligonucleotides. In: Gene Regulation: Biology of Antisense RNA and DNA. Erickson R and Izant JF (eds). Raven Press Ltd., New York, pp147-161, 1992.

22. Cheng K, Yang N and Mahato RI: TGF- $\beta 1$ gene silencing for treating liver fibrosis. Mol Pharm 6: 772-779, 2009.

23. Wilkins-Port CE and Higgins PJ: Regulation of extracellular matrix remodeling following transforming growth factor-beta1/ epidermal growth factor-stimulated epithelial-mesenchymal transition in human premalignant keratinocytes. Cells Tissues Organs 185: 116-122, 2007.

24. Dasgupta S, Bhattacharya-Chatterjee M, O'Malley BW Jr and Chatterjee SK: Tumor metastasis is an orthotopic murine model of head and neck cancer: possible role of TGF-beta 1 secreted by the tumor cells. J Cell Biochem 97: 1036-1051, 2006.

25. Sun L, Diamond ME, Ottaviano AJ, Joseph MJ, Ananthanarayan V and Munshi HG: Transforming growth factor- $\beta 1$ promotes matrix metalloproteinase-9-mediated oral cancer invasion through Snail expression. Mol Cancer Res 6: 10-20, 2008.

26. Munshi HG, Wu YI, Mukhopadhyay S and et al: Differential regulation of membrane type 1-matrix metalloproteinase activity by ERK $1 / 2$ - and p38 MAPK-modulated tissue inhibitor of metalloproteinases 2 expression controls transforming growth factor-beta 1-induced pericellular collagenolysis. J Biol Chem 279: 39042-39050, 2004. 